\title{
Some tests on the effect of edge restraint on punching shear in reinforced concrete slabs*
}

by R. Taylor, B.Sc., D.I.C., A.M.I.C.E. and B. Hayes, B.Sc.

\section{Contribution by H. G. Russell, B.Eng. University of Sheffield}

Although the authors do not define their percentage of reinforcement, it would seem that an error has been introduced into column 2 of Table 1. A figure of $0.92 \%$ of the cross-sectional area bounded by the effective depth would seem more appropriate for series 2 and $1.84 \%$ for series 3 . However, this error has not been introduced into the calculation of the flexural failure load.

For the unrestrained slabs of series 2, it is stated that punching shear failure did not occur until the reinforcement below the concentrated load had yielded. Therefore, it would seem that the failure resulted from the collapse of the compression zone after yielding of the reinforcement. In this case the failure is really a flexural collapse and the shearing force only changes the mode of failure after the compression zone has collapsed from excess bending moment.

The effects of a restraint similar to that used by the authors can be divided into three categories which are interrelated in the slab. They will be considered separately in order to give a clearer understanding.

(a) When the load on the test slab is increased, the slab deflects and transverse compressive stresses are induced because of the restraint against sideways expansion. These stresses are similar to those depicted by Ockleston $^{(1)}$ in his Perspex model and described by Wood ${ }^{(2)}$.

(b) The rigid outer frame prevents the outer edges of the slab from rotating. This introduces a reverse bending moment around the outer edge of the slab.

(c) For the slabs with restrained sides, vertical frictional forces develop between the mortar and the frame. These prevent the corners of the slab from lifting but when the restraint is absent the corners appear to be free to lift. A different pattern of bending moments results for the two cases and a different yield-line mechanism forms. This is not considered by the authors when calculating the flexural failure load in Table 1.

Item (a) is always present when the deflexion of the slab is small compared to its total thickness. Its effect is greatest when the size of the loaded area is largest. Items (b) and (c) tend to reduce the bending moments at the edge of the load and the ultimate load increases since the failure is largely one of flexural collapse.

*Pages 39 to 44 of Magazine No. 50.
The development of any restraining or supporting action of the type listed above depends upon the deformation of the slab outside the supporting rollers. With the type of restraint used by the authors, this depended upon the deformation of the concrete, mortar and restraining frame. Since the deformation of the loading frame would be less than that of the concrete and mortar, it is to be expected that the restraint would be more effective if it were fixed closer to the supporting rollers, provided that it was still a good fit against the slab edges.

The formation of any restraining force depends also upon the deflexion of the slab. For series 3, with double the percentage of reinforcement, the deflexions are not as great as for series 2 , and the induced forces and restraining moments are proportionately less. Therefore the percentage increase in the ultimate load is lower than for series 2 , as the test results showed.

\section{Contribution by Edward G. Nawy, D.I.C., C.E.(MIT), F.A.S.C.E., M.I.C.E. Rutgers State University}

The authors have presented a valuable contribution on the punching shear behaviour of simply supported versus confined slabs. I would like to add more supporting evidence on some aspects of the work reported. In these tests, $5 \mathrm{ft} 8$ in. square slabs were centrally loaded ${ }^{(3)}$, and the restrained slab CSFI failed at a load $86 \%$ of the computed theoretical flexural capacity. Failure seemed to be in simultaneous flexural and punching shear collapse, because of incomplete restraint at the four boundaries. In the further tests at present being conducted, where more complete restraint is being imposed, punching shear has been prevented although the same type of shear reinforcement as in slab CSFI has been used. This observation is in full accord with the first conclusion of Messrs Taylor and Hayes.

In comparing Figures 4 and 6 of the paper, both show an almost identical spacing of cracks though the steel percentage in series 3 was twice that in series 2 . Investigations ${ }^{(3,4)}$ have shown that crack spacing is a function not only of reinforcement spacing in two-way slabs but also of the "stretched" area of concrete in the tensile zone. Since it is not clear from the paper whether the concrete cover in series 3 was different from that in series 2 , and hence whether the areas of stretched concrete were different, the authors are asked to elaborate and, if possible, to publish the crack 
widths and spacings obtained in this research programme.

\section{Reply by the authors}

We are grateful to Mr Russell for pointing out the errors in the quoted percentages of reinforcement. As he says, these errors were not introduced into the calculations.

The statements in Mr Russell's second paragraph are essentially similar to those in the paper. It was concluded by the authors that, although the punching shear failures of the simply supported slabs of series 2 gave load factors less than 3 , these were adequate in view of the load-deflexion characteristics of these slabs, i.e. in view of the fact that the slabs were at or near flexural failure. The load factor to be used in translating test data to permissible values for design is very dependent on the type of failure.

The restraining forces acting on a slab are complex but the dominant effect is that produced by the restraint to the lower edges of the slab against lateral expansion. The upper edges of the slab tend to move inwards and top cracking between the frame and the top edges was observed in all the tests on restrained slabs. Thus it is not understood what Mr Russell means in item (b) when he states that a reverse bending moment is imparted to the edges of the slab. This is not so. Certainly vertical frictional forces develop and these affect the bending moment distribution in the slab. However, although these forces prevent the corners from lifting, top cracking also occurs across the corners and, as there was no top reinforcement, the same mechanism can form in both the simply supported and the restrained cases.
The investigation was largely exploratory and aimed only at a direct comparison of identical slabs in restrained and simply supported conditions. Different arrangements for carrying out the tests may affect the results slightly and it is perhaps pertinent to remark that the conclusions presented are applicable only to the conditions of the tests. One aim of the tests was to determine whether further programmes of work with more refined methods of testing would be worth while.

It is interesting to hear that the preliminary tests of Professor Nawy support the work presented. We are of the opinion that the spacing of the reinforcement had the biggest effect on the spacing of the cracks which ran parallel to the sides of the slab. Most of these cracks are initiated at the position of a reinforcing bar. Since the spacing of the bars in both series was the same, it is perhaps not surprising that their crack patterns are similar. It is regretted that no data on crack widths and spacing are available. The cover to the reinforcement was the same in all the slabs.

\section{REFERENCES}

1. OCKLESTON, A. J. Arching action in reinforced concrete slabs. The Structural Engineer. Vol. 36. June 1958. pp. 197-201.

2. WOOD, R. H. Plastic and elastic design of slabs and plates. London, Thames and Hudson, 1961. pp. 344.

3. NAWY, E. G. Flexural cracking in two-way concrete slabs reinforced with high strength welded wire fabric. Journal of the American Concrete Institute. Proceedings Vol. 00. March 1965. pp. 1737-1739.

4. NAWY, E. G. Flexural cracking propogation in two-way concrete slabs reinforced with high strength welded wire fabric. Rutgers University Report. November 1963. Reprinted April 1965. 